\title{
What Are the Advantages of 3D Cameras in Gynaecological Laparoscopy?
}

\author{
Welche Vorteile bringt der Einsatz von 3-D-Kameras \\ in der gynäkologischen Laparoskopie?
}

Authors

S. Baum ${ }^{1,2}$, M. Sillem ${ }^{3}$, J. T. Ney ${ }^{4}$, A. Baum ${ }^{5}$, M. Friedrich ${ }^{6}$, J. Radosa ${ }^{2}$, K. M. Kramer ${ }^{7}$, B. Gronwald ${ }^{8}$, S. Gottschling ${ }^{9}$, E. F. Solomayer ${ }^{4}$, A. Rody ${ }^{1}$, R. Joukhadar ${ }^{10}$

\section{Affiliations}

1 Klinik für Frauenheilkunde und Geburtshilfe, UKSH Klinik für Frauenheilkunde und Geburtshilfe Campus Lübeck, Lübeck, Germany

2 Universitätsklinikum des Saarlandes, Klinik für Frauenheilkunde und Geburtshilfe, Homburg/Saar, Germany

3 Praxisklinik am Rosengarten, Mannheim, Germany

4 Klinik für Frauenheilkunde, Geburtshilfe und Reproduktionsmedizin, Universitätsklinikum des Saarlandes, Homburg/Saar, Germany

5 Praxis Prof. Dr. Dhom \& Partner, Ludwigshafen, Germany

6 Frauenklinik, HELIOS-Klinikum Krefeld, Krefeld, Germany

7 Viszera Chirurgie-Zentrum, Munich, Germany

8 Zentrum für Palliativmedizin und Kinderschmerztherapie, Universitätsklinikum des Saarlandes, Homburg, Germany

9 Universitätsklinikum des Saarlandes, Zentrum für Palliativmedizin und Kinderschmerztherapie, Homburg/Saar

10 Universitätsfrauenklinik Würzburg, Würzburg, Germany

Key words

laparoscopy, 3D, advantage, clinical use

Schlüsselwörter

Laparoskopie, 3-D, Vorteil, klinischer Nutzen

received $\quad 27.4 .2016$

revised 22.9.2016

accepted 9.11.2016

Bibliography

DOI http://dx.doi.org/10.1055/s-0042-120845

Geburtsh Frauenheilk 2017; 77: 45-51 @ Georg Thieme Verlag KG Stuttgart · New York | ISSN 0016-5751

Correspondence

Dr. Sascha Baum

UKSH Klinik für Frauenheilkunde und Geburtshilfe Campus Lübeck Ratzeburger Allee 160, 23538 Lübeck, Germany

sascha.baum@uksh.de

Deutsche Version unter:

http://dx.doi.org/10.1055/s-0042-120845

\section{ABSTRACT}

Introduction Minimally invasive operative techniques are being used increasingly in gynaecological surgery. The expansion of the laparoscopic operation spectrum is in part the result of improved imaging. This study investigates the practical advantages of using 3D cameras in routine surgical practice.

Materials and Methods Two different 3-dimensional camera systems were compared with a 2-dimensional HD system; the operating surgeon's experiences were documented immediately postoperatively using a questionnaire.

Results Significant advantages were reported for suturing and cutting of anatomical structures when using the 3D compared to 2D camera systems. There was only a slight advantage for coagulating. The use of $3 \mathrm{D}$ cameras significantly improved the general operative visibility and in particular the representation of spacial depth compared to 2dimensional images. There was not a significant advantage for image width. Depiction of adhesions and retroperitoneal neural structures was significantly improved by the stereoscopic cameras, though this did not apply to blood vessels, ureter, uterus or ovaries.

Conclusion 3-dimensional cameras were particularly advantageous for the depiction of fine anatomical structures due to improved spacial depth representation compared to 2D systems. 3D cameras provide the operating surgeon with a monitor image that more closely resembles actual anatomy, thus simplifying laparoscopic procedures.

\section{ZUSAMMENFASSUNG}

Einleitung In der gynäkologischen Chirurgie sind minimalinvasive Operationsmethoden zunehmend auf dem Vormarsch. Die Erweiterung des laparoskopischen OP-Spektrums resultiert u. a. aus einer zunehmenden Verbesserung der Bildgebung. In dieser Arbeit wird untersucht, welche praktischen Vorteile der Einsatz von 3-D-Kameras in der operativen Routine mit sich bringt.

Material und Methoden Es wurden 2 unterschiedliche 3-dimensionale Kamerasysteme mit einem 2-dimensionalen HD-System verglichen. Direkt postoperativ wurden hierzu die Erfahrungen der Operateure mittels Fragebogen erhoben.

Ergebnisse Im Vergleich zum 2-D-Kamerasystem ergaben sich signifikante Vorteile durch die Verwendung von 3-D-Kamerasystemen beim Nähen und Schneiden von Strukturen. Dagegen waren die Vorteile beim Koagulieren nur gering. Die allgemeinen Sichtverhältnisse und insbesondere die Tiefendarstellung des Raumes war durch die Verwendung von 3-D-Kameras signifikant verbessert im Vergleich zum 2-dimensionalen Bild. Dagegen zeigte sich in der Bildbreitendarstellung kein signifikanter Vorteil der stereoskopischen Kameras. Die Darstellung von Adhäsionen und nervalen Strukturen des Retroperitoneums zeigte sich bei 3-D-Kameras signifikant verbessert. Diese Signifikanz war bei Gefäßen, Ureter, Uterus und Ovarien nicht gegeben.

Schlussfolgerung Durch die räumliche Tiefendarstellung ergaben sich besonders signifikante Vorteile gegenüber 2-dimensionalen Ka- 
meras bei der Darstellung feiner anatomischer Strukturen. Mit dem Einsatz von 3-D-Kameras wird dem Operateur ein dem realen Situs näheres Monitorbild vermittelt. Daraus resultiert eine Erleichterung des laparoskopischen Operierens.

\section{Introduction}

In recent years there has been a sharp increase in the use of minimally invasive operative techniques in gynaecological surgery. Various studies have shown that minimally invasive surgery has advantages over open surgery for simple and moderately difficult procedures [1-5].

The expansion of the spectrum of laparoscopic operations is largely due to technical advances. These include the development of special instrumentation, e.g. ultrasonic scissors, and most importantly, improved optics. The introduction of HD (= high definition) cameras and monitors improved the visual depiction of anatomical structures, which operating surgeons experience as advantageous, and improves operative safety [6].

A 3-dimensional camera system was used in gynaecology for the first time in 1993 [7]. The stereoscopic, i.e. 3-dimensional $(=3 \mathrm{D})$ view lead to a significant reduction of time in operative steps. This time-saving was particularly relevant for complex procedures [8].

With the da Vinci robotic surgical system a 3D camera system was widely used in endoscopic surgery for the first time. This system is an expensive alternative to open and laparoscopic surgery.

For example, given sufficient case numbers, the extra cost of a pyeloplasty using a robot instead of laparoscopic surgery is estimated at $20 \%$ [9]. Today more and more 3D camera systems of various types are becoming available for conventional laparoscopic surgery.

In our hospital we offer the full spectrum of laparoscopic operations, including radical carcinoma surgery. These procedures are mostly performed using a 2D video system, though the da Vinci operating robot is also used.

From the patient perspective the minimally invasive surgical approach has significant advantages, such as less postoperative pain and need for analgesics, shorter hospital stay, quicker return to normal daily activities and, not least, better cosmetic results $[10,11]$.

Despite these patient factors laparoscopic surgery has a number of disadvantages from the surgeon's perspective, such as limited scope for movement and restricted instrument ergonometry, which together result in increased stress levels for the operating surgeon [11-13]. Technical innovations can reduce this stress. We tested two 3D camera systems to investigate whether, and in which surgical situations, 3D intraoperative imaging is advantageous. The benefits of 3D laparoscopy systems with respect to precision and efficiency have been shown under experimental conditions in numerous studies [14-19]. In our study the systems were implemented in real, everyday surgical situations.

Two skills are paramount for performing laparoscopic surgery: firstly the ability to convert 2D information into a 3D understanding of the anatomy, and secondly hand-eye coordination [20].

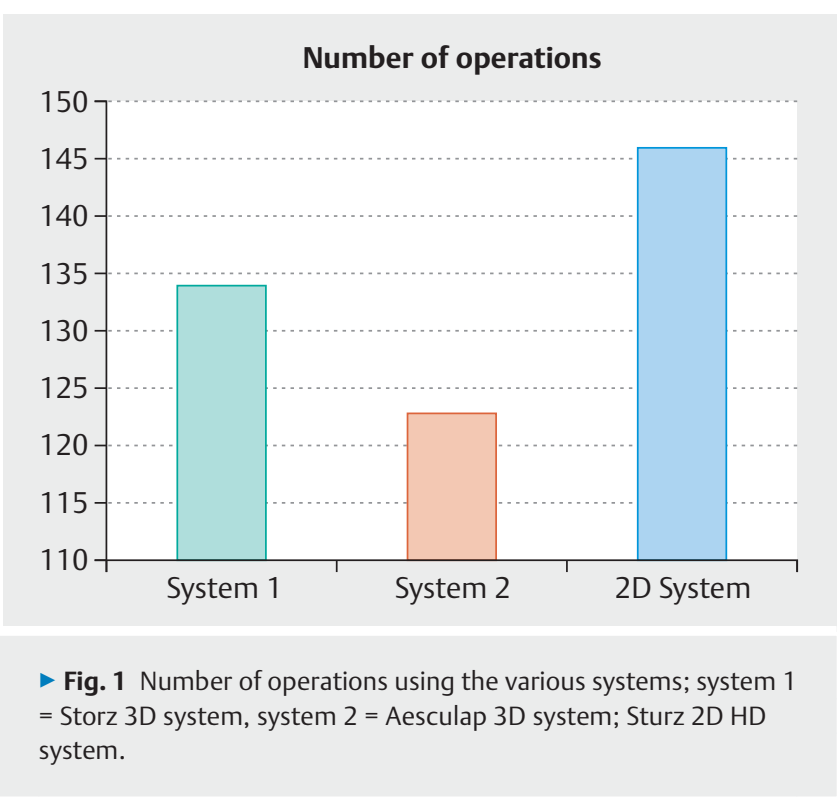

The aim of this study was to test the suitability of 3D camera systems for everyday use and to elucidate whether, and in which operative situations, 3D imaging is beneficial compared to 2D systems.

\section{Materials and Methods}

\section{Test modalities}

Two 3D camera systems were tested by a total of 5 experienced surgeons. Following initial training in the use of the systems by product representatives from the respective firms there was a 3week familiarisation phase in which the 5 trained operating surgeons undertook operations of all grades of difficulty in order to develop a degree of routine in using the camera systems, and to become accustomed to the $3 \mathrm{D}$ view.

Thereafter followed the actual test phase of the study in which both systems were in routine use on a daily basis over a number of consecutive weeks.

The systems were used for operations of diverse levels of difficulty, the surgeons completing a questionnaire after each procedure. In addition to the set questions the questionnaire allowed for free comment on the imaging apparatus used.

A total of 257 operations were performed using both 3D camera systems. Of these, 134 were performed with the 3D camera from the manufacturer Storz, and 123 with the camera manufactured by Aesculap. An additional 146 operations were performed with the Storz 2D system ( $\bullet$ Fig. 1 ). 


\section{Study laparoscopy systems}

The systems tested were the Karl Storz 3-D-System (Karl Storz $\mathrm{GmbH} \&$ Co. KG, Tuttlingen), in this article subsequently referred to as system 1, and the EinsteinVision ${ }^{\circledR}$ System (Aesculap AG \& Co. KG, Tuttlingen/B. Braun Melsungen AG, Melsungen), subsequently referred to as system 2. Modified versions of both systems are now available, thus neither of the producers will have been disadvantaged by this article. (Indeed, the Aesculap system has since been significantly modified and is no longer controlled by the robotic arm described here). The tested systems differed fundamentally in terms of camera control: the camera of the Aesculap EinsteinVision ${ }^{\circledR}$ system was steered using a remotely controlled robotic arm in a sterile sleeve; the Storz 3D camera was guided freehand.

\section{Data acquisition}

The questionnaire contained 9 main questions, some of which were subdivided into further questions making a total of 18 questionnaire points ( $\bullet$ Table $\mathbf{1}$ ).

Each questionnaire point was rated from 1 to 5 with 1 representing a significant improvement, and 5 a negative rating. The systems were used in routine practice on an alternating basis.

\section{Statistics}

Statistical analysis was carried out with the program SOFA Statistics version 1.4.1. Analysis of the normally distributed groups was conducted using the Mann-Whitney $\mathrm{U}$ test, Fisher's exact test and the $x^{2}$ test.

\section{Results}

\section{Camera control}

Although the two camera systems were constructed very differently, they received similar ratings from surgeons. The mean score of 2.37 (median $=2 ; \mathrm{SD}=0.90$ ) for the Aesculap system was almost identical to that (2.38) of the Storz unit (median $=2$; $\mathrm{SD}=0.99$ ). With a p-value of 0.853 the difference between the systems was not significant.

Since the external assembly of the Storz 3D system did not differ from the $2 \mathrm{D}$ system from the same manufacturer, the camera guidance of the 2D system was not assessed separately. In the free comments section of the questionnaire it was repeatedly reported that the 3D camera heated up more markedly than the 2D camera and this was experienced as uncomfortable.
- Table 1 List of study parameters.

\begin{tabular}{l} 
Camera control \\
View \\
- General visibility \\
- Spacial depth \\
- Image width \\
Manual actions \\
- Suturing \\
- Coagulating \\
- Cutting \\
Depiction of anatomical structures \\
- Blood vessels \\
- Ureter \\
- Uterus \\
- Ovaries \\
- Adhesions \\
- Retroperitoneum \\
Movement \\
\hline Lens fogging \\
\hline Overall assessment compared to 2D systems \\
Autofocus function (only offered by one system) \\
\hline Instrumentation
\end{tabular}

\section{Manual actions}

The manual actions evaluated were coagulating, cutting anatomical structures and suturing.

- Table 2 shows the mean scores and p-values achieved by the different 3D systems for each of these actions. No significant differences were found between the two systems.

- Table 3 shows the manual actions for all three systems. On comparison of system 1 with the 2D HD system it is notable that suturing (system 1: mean 1.63 vs. $2 \mathrm{D}$ system: mean 3.4; $\mathrm{p}=0,044$ ) and cutting (system 1 : mean 1.71 vs. $2 \mathrm{D}$ system: mean 2.8; $\mathrm{p}=0.049$ ) were significantly improved using $3 \mathrm{D}$ imaging. Coagulation was only slightly, non-significantly improved (system 1 : mean 2.52 vs. $2 \mathrm{D}$ system: mean $3.1 ; p=0.11$ ).

Performing manual actions with system 2 was also improved compared to the 2D system, for suturing (system 2: mean 1.67 vs. $2 \mathrm{D}$ system: mean $3.4 ; \mathrm{p}=0.047$ ) and dissecting (system 2: mean 1.77 vs. 2D system: mean 2.8; $p=0.0496$ ) significantly, and for coagulating non-significantly (system 2: mean 2.42 vs. 2D system 3.1; $\mathrm{p}=0.093)(\triangleright$ Table 3$)$.

- Table 2 Rating of manual actions for the different 3D systems.

\begin{tabular}{|l|l|l|l|}
\hline & System 1 (mean) & System 2 (mean) & p-value \\
\hline Suturing & 1.63 & 1.67 & 0.83 \\
\hline Cutting & 1,71 & 1.77 & 0.86 \\
\hline Coagulating & 2.2 & 2.42 & 0.73 \\
\hline
\end{tabular}


- Table 3 Manual actions for 3D systems 1 and 2 compared to the 2D system.

\begin{tabular}{|l|l|l|l|l|l|l|}
\hline & System 1 (mean) & 2D system & p-value & System 2 (mean) & 2D system & p-value \\
\hline Suturing & 1.63 & 3.4 & 0.044 & 1.67 & 3.4 & 0.047 \\
\hline Dissecting & 1.71 & 2.8 & 0.049 & 1.77 & 2.8 & 0.0496 \\
\hline Coagulating & 2.52 & 3.1 & 0.11 & 2.42 & 3.1 & 0.093 \\
\hline
\end{tabular}

- Table 4 Mean scores of the different camera systems for depiction of various anatomical structures.

\begin{tabular}{|l|l|l|l|l|l|l|}
\hline & $\begin{array}{l}\text { Blood vessels } \\
\text { (mean) }\end{array}$ & $\begin{array}{l}\text { Ureter } \\
\text { (mean) }\end{array}$ & $\begin{array}{l}\text { Uterus } \\
\text { (mean) }\end{array}$ & $\begin{array}{l}\text { Ovaries } \\
\text { (mean) }\end{array}$ & $\begin{array}{l}\text { Adhesions } \\
\text { (mean) }\end{array}$ & $\begin{array}{l}\text { Retroperitoneum } \\
\text { (mean) }\end{array}$ \\
\hline System 1 & 2.25 & 2.31 & 1.91 & 1.75 & 1.41 & 1.32 \\
\hline System 2 & 1.96 & 2.44 & 1.83 & 1.81 & 1.45 & 1.42 \\
\hline 2D system & 2.83 & 2.83 & 2.79 & 2.58 & 2.67 & 3.01 \\
\hline
\end{tabular}

\section{General visibility and spacial (operative field) depth}

Operative visibility in general was rated better for both 3D systems compared to the $2 \mathrm{D}$ system (system 1: mean 1.44; median $=1, S D=0.63$ and system 2: mean 1.60; median $=2$, $\mathrm{SD}=0.64$ vs. $2 \mathrm{D}$ system: mean 3.1 ; median $=2, \mathrm{SD}=0.51$ ). There was no difference between the two 3D cameras on comparison with one another (system 1: mean 1.44 vs. system 2: mean 1.6; $\mathrm{p}=0.53)$.

The subjective improvement in general visibility with 3D technology vs. the $2 \mathrm{D}$ lens was significant for both system 1 (mean 1.44 vs. $3.1 ; p=0.041$ ) and system 2 (mean 1.60 vs. 3.1; $\mathrm{p}=0.049$ ) respectively.

Similar to these findings for general visibility, the two 3D units did not differ from one another in their ratings for spacial depth depiction. The mean score for the Aesculap system was 1.49 (median $=1 ; S D=0.56$ ) and for the Storz unit 1.63 (median=2; $\mathrm{SD}=0.62 ; \mathrm{p}$-value $=0.15$ ). In comparison, the $2 \mathrm{D}$ system had a mean score of 3.24 for this parameter (median $=2$; $S D=0.64$ ) making the improvement significant for system 1 (mean 1.63 vs. $3.24 ; p=0.019$ ) and highly significant for system 2 (mean 1.49 vs. $3.24 ; \mathrm{p}=0.01$ ) compared to the $2 \mathrm{D}$ camera.

\section{Image (operative field) width}

For image width system 1 was rated at a mean score of 2.51 and system 2 at a mean of 2.48; a non-significant difference $(p=0.88)$ between the systems.

The 2D camera system was rated at a mean of 2.63 so that for this parameter there was no significant difference compared to system $1(p=0.83)$ or system $2(p=0.78)$.

\section{Depiction of anatomical structures}

- Table $\mathbf{4}$ shows the mean scores of the different camera systems for the depiction of various pelvic anatomical structures. For the retroperitoneum the ability to visualise neural structure was rated.

There were no significant differences between the two 3D camera systems for the various anatomical structures. Both 3D sys- tems improved visualisation of the uterus and ovaries but not significantly. In contrast, they improved visualisation of nerves (mean 1.32 [system 1] vs. mean 3.01 [2D system], $\mathrm{p}=0.03$; mean 1.42 [system 2] vs. mean 3.01 [2D system], $p=0.04$ ) and adhesions (mean 1.41 [system 1] vs. mean 2.67 [2D system], $\mathrm{p}=0.0497$; mean 1.45 [system 2] vs. mean 2.67 [2D system], $\mathrm{p}=0.0499$ ) significantly in comparison to $2 \mathrm{D}$ depiction.

\section{Movement}

Since the Aesculap camera system was guided by a robotic arm no comparison was made with the manually controlled cameras. Only differences between the Storz 3D and 2D systems were captured. The mean score of 2.11 (median $=2$; $S D=0.39$ ) for the 2D camera was not significantly different to the mean of 2.83 (me$\operatorname{dian}=2 ; S D=0.55)$ for the $3 D$ camera (Storz) $(p=0.37)$. In the free comment section it was noted, however, that rapid movements with the $3 \mathrm{D}$ camera sometimes caused the surgeons to feel dizzy.

\section{Lens fogging}

Fogging over of the lens is a well-known technical problem in laparoscopy. The manually controlled Storz systems had the advantage that they could be removed from the operative field for cleansing much more quickly than the Aesculap system, which was fixed by a robotic arm. For this reason we only analysed the frequency of lens fogging.

The mean score for the 2D system was 2.94 (median = 3; $\mathrm{SD}=0.21$ ); the mean for system 1 was 3.01 (median=3; $\mathrm{SD}=0.36$ ) and for system 2 was 2.86 (median $=3$; $S D=0.33$ ) ( $p=0.57$ for comparison of the two 3D systems to one another, $p=0.87$ for comparison of system 1 to $2 D$, and $p=0.84$ for comparison of system 2 to 2D).

\section{Overall comparison of 3D and 2D systems}

Here surgeons were questioned whether, in their opinion, the use of $3 \mathrm{D}$ cameras improves/simplifies operating conditions. 
The Storz 3D system was rated at a mean score of 1.94 and the Aesculap camera at 1.89 ( $p=0.87$ between the two 3D cameras). The 2D camera was rated at mean of 2.67. The improvement was not significant for both system $1(p=0.08)$ and system 2 $(p=0.073)$ on comparison with the $2 \mathrm{D}$ lens.

\section{Autofocus}

Only the Storz system had an integrated autofocus, which was found to react quickly and function reliably in routine use. It received an average score of 1.63 for the 134 operations (me$\operatorname{dian}=2, \mathrm{SD}=0.62$ ).

\section{Discussion}

Both 3D systems proved suitable for routine use in our setting. The systems differed in that the Aesculap EinsteinVision ${ }^{\circledR}$ camera offered full HD resolution and robotic arm control, whereas the 3D camera manufactured by Storz had an integrated autofocus that automatically regulated image sharpness. Despite these differences the two camera concepts received similar ratings for controllability by surgeons ( 2.38 for manual control and 2.37 for robotic arm).

This very similar rating may have resulted from the fact that the two systems were not used in parallel, but rather on an alternating basis over a period of weeks. Both cameras had their advantages: surgeons appreciated the reliable autofocus on the one, and by the more realistic anatomical depiction of the other. The ideal solution would seem to be a combination of these two technologies.

The value of recently available 4K 2D technology (4-fold HD resolution) compared to $3 \mathrm{D} \mathrm{HD}$ technology has not yet been studied.

The two study systems both had advantages and disadvantages in terms of camera control. The Aesculap camera was significantly bigger and heavier than the Storz camera, making prolonged manual steering problematic. However the robotic arm control allowed continuous movement and made smaller procedures possible practically without the need for an assistant.

In contrast, the much smaller and lighter Storz camera could be manually controlled even for longer operations without difficulty. The disadvantage was relatively marked heat generation, which surgeons found uncomfortable.

Since there was not a comparable robotic arm system from the Storz company, this camera was not rated on this point.

3D monitors have a lower levels of brightness than 2D monitors, meaning that the operating room must be dimmed more strongly [26]. Also, to achieve the 3-dimensional effect special glasses must also be worn, which surgeons often found uncomfortable $[27,30]$. Both points are considered technical disadvantages of 3D imaging.

As shown in - Tables 2, $\mathbf{3}$ and $\mathbf{4}$ both stereoscopic cameras achieved very good (and comparable) results for suturing and cutting (no significant difference between cameras). In comparison, the 2D HD camera system was rated significantly worse. Results were different for the third manual action, coagulation. For this parameter there were not significant differences between the two 3D systems and the 2D lens.

Coagulating under 3D imaging was rated noticeably worse than the other manual actions. The reason for this - as noted in the free comment section - was the more vivid depiction of coagulation smoke particles, which surgeons found bothersome. Our analysis is consistent with the findings of numerous other authors who have shown that the use of stereoscopic cameras improves manual actions. However, in contrast to our study, these trials examined standardised manual procedures in the laboratory setting, with the measured parameter being time [21-25, 27,34, 41, 45-47].

Using a 2D system causes a change in visual perception through reduced depiction of spatial depth [28]. 2D laparoscopy is more challenging for surgeons than open surgery because of this loss of depth perception [29,30]. 3D laparoscopy attempts to resolve this perceptual problem: these $3 \mathrm{D}$ video systems bring stereoscopic vision back to the endoscopic surgeon [32-37].

Wey et al. showed that visual misinterpretation in 2-dimensional laparoscopy was responsible for $97 \%$ of errors during laparoscopic surgery [31], and Alarami et al. found that the improved depth perception provided by 3D laparoscopy improves the quality of laparoscopic surgery, and may also improve patient safety [27].

General visibility did not differ significantly between the two $3 \mathrm{D}$ systems used in this study with ratings of 1.44 for system 1 and 1.6 for system 2 . In contrast, it was significantly better with both stereoscopic cameras compared to the $2 \mathrm{D}$ lens. There was only a slight difference between the two 3D cameras for spatial depth representation, whereas the differences between the $2 \mathrm{D}$ camera and the two 3D cameras were significant to very significant ( $p$-values $=0.019$ and 0.01 respectively). Analogous to our study Jones et al. found that the improved depth depiction was the most important advantage of 3D camera systems [41]. This result is also supported by notes in the free comment section of the questionnaire.

Whereas the 3D system provided major improvements in spatial depth appreciation, there were only marginal differences between the two camera units in terms of image width.

There were no major differences between the two 3D camera systems in terms of viewing the various anatomical structures, including adhesions.

On comparison with the 2-dimensional system, both 3D cameras provided better images of the uterus, ovaries, ureters and blood vessels (difference non-significant), and significantly improved depiction of adhesions and retroperitoneal nerves.

Thus 3D lens technology was particularly advantageous for finer structures (such as adhesions and nerves), and less so for larger anatomical structures (such as ureters, blood vessels, ovaries and uterus).

On analysis of camera mobility the manually controlled 3D camera was rated worse than the 2D system, though the difference was non-significant. (No comparison was made between the Storz system and the much bigger, heavier Aesculap camera, which, because of its size and weight, was mainly controlled via robotic arm). The reason for this poor rating was identified in the free comment section of the questionnaire: Surgeons reported 
that quick movements with the 3D camera repeatedly caused brief dizziness and nausea, which was experienced as unpleasant. This has been known to be one of the problems with 3D technology for some time, as reported by Mueller et al. and Chan et al. $[25,38,39]$. A stereoscopic error can be assumed causative, since the setting was the same for all surgeons. These unwanted effects such as headache, dizziness and nausea have often been described, the individual studies reporting them, however, coming to varying conclusions [30,40-43].

Overall, however, it is evident that these unwanted effects of 3D technology are reported less often in more recent studies, most likely due to improved image quality [27, 30, 34, 44].

Lens fogging, which results from e.g. coagulating or inserting the camera lens from the relatively cool room temperature into the warmer peritoneal cavity, occurred to the same extent with all lenses.

On overall rating of the 2D camera (mean 2.67) compared to the two 3D units (system 1: mean 1.94; system 2: mean 1.89) there was a clear, yet non-significant difference ( $p$-value $=0.08$ and 0.073 for systems 1 and 2 respectively).

Despite very different construction, both these 3D camera systems improve surgical conditions, providing benefit for surgeons and patients alike.

\section{Conclusions}

\section{For the surgeon}

This 3D technology provides surgeons with additional information on spatial depth and improved, vivid depiction of anatomical structures. As a result, performing manual procedures is simplified; the camera imaging of the surgical field more closely resembles operating conditions at open surgery.

For the surgeon, this more realistic anatomical depiction may reduce stress.

\section{For the patient}

This 3D technology simplifies the performance of more difficult operative steps, which may reduce operating time. These operator advantages improve patient safety.

In addition it is possible to perform more complex operations using the minimally invasive approach. For the patient, this means shorter convalescence compared to open surgery.

A weakness of this study is that the results are based on the subjective assessment of surgeons and not on objective measures of standardised procedures.

However herein also lies the strength of the study. We tested to what extent 3D technology was advantageous for a large number of operations of all levels of difficulty, and whether it was suitable for routine use.

Overall 3D imaging improved operative visibility, particularly through adding spacial depth appreciation. This additional aspect of vividness firstly was of significant benefit for the depiction of anatomy, particularly finer structures, and secondly it significantly simplified complex surgical procedures such as suturing.

In this study 3D technology proved fully suitable for routine use. It significantly improved operating conditions, for the sur- geon simplifying procedures, and as a consequence, improving patient safety.

Conflict of Interest

None.

References

[1] Dagher I, Di Giuro G, Dubrez J et al. Laparoscopic versus open right hepatectomy: a comparative study. Am J Surg 2009; 198: 173-177

[2] Keus F, de Jong JA, Gooszen HG et al. Laparoscopic versus open cholecystectomy for patients with symptomatic cholecystolithiasis. Cochrane Database Syst Rev 2006; (4): CD006231

[3] Laine S, Rantala A, Gullichsen R et al. Laparoscopic vs. conventional Nissen fundoplication: a prospective randomized study. Surg Endosc 1997; 11: 441-444

[4] Medeiros LR, Stein AT, Fachel J et al. Laparoscopy versus laparotomy for benign ovarian tumor: a systematic review and meta-analysis. Int J Gynecol Cancer 2008; 18: 387-399

[5] Sauerland S, Lefering R, Neugebauer EA. Laparoscopic versus open surgery for suspected appendicitis. Cochrane Database Syst Rev 2004; (4): CD001546

[6] Van Bergen P, Kunert W, Buess GF. The effect of high-definition imaging on surgical task efficiency in minimally invasive surgery: an experimental comparison between three-dimensional imaging and direct vision through a stereoscopic TEM rectoscope. Surg Endosc 2000; 14: 71-74

[7] Wenzl R, Pateisky N, Husslein P. Erstmaliger Einsatz eines 3D-Videoendoskopes in der Gynäkologie. Geburtsh Frauenheilk 1993; 53: 776-778

[8] Wagner OJ, Hagen M, Kurmann A et al. Three-dimensional vision enhances task performance independently of the surgical method. Surg Endosc 2012; 10: 2961-2968

[9] Kommu SS, Murphy D, Patel SP. Robot-assisted pyleoplasty vs. laparoscopic pyeloplasty - a preliminary cost comparison in United Kingdom setting. Proceedings of the 24th World Congress of Endourology; 2006; Cleveland, OH, USA: A224

[10] Ahmed I, Paraskeva P. A clinical review of single-incision laparoscopic surgery. Surgeon 2011; 9: 341-351

[11] Xin H, Zelek J, Carnahan H, eds. Laparoscopic Surgery, perceptual Limitation and Force: a Review. First canadian Student Conference on biomedical Computing; 2006. Kingston, Ontario Canada. Online: https:// www.researchgate.net/profile/John_Zelek2/publication/237774967_ Laparoscopic_surgery_perceptual_limitations_and_force_A_review/ links/0f31752dd5bf019665000000.pdf; last access: 20.01.2014

[12] Szeto GP, Cheng SW, Poon JT et al. Surgeons' static posture and movement repetitions in open and laparoscopic surgery. J Surg Res 2012; 172 : e19-e31

[13] Dakin G, Gagner M. Comparison of laparoscopic skills performance between standard instruments and two surgical robotic systems. Surg Endos 2003; 17: 574-579

[14] Bueß GF, van Bergen P, Kunert W et al. Vergleichsstudie verschiedener 2D- und 3-D-Sichtsysteme in der minimal-invasiven Chirurgie. Chirurg 1996; 67: 1041-1046

[15] Crosthwaite G, Chung T, Dunkley P et al. Comparison of direct vision and electronic two- and three dimensional display systems on surgical task efficiency in endoscopic surgery. Br J Surg 1995; 82: 849-851

[16] Peitgen K, Walz MV, Holtmann G et al. A prospective randomized experimental evaluation of three-dimensional imaging in laparoscopy. Gastrointest Endosc 1996; 44: 262-267 
[17] Storz P, Buess G, Kunert W et al. 3D HD versus 2D HD: surgical task efficiency in standardised phantom tasks. Surg Endosc 2012; 26: 14541460

[18] Leite M, Carvalho AF, Costa P et al. Assessment of laparoscopic skills performance: $2 \mathrm{D}$ versus $3 \mathrm{D}$ vision and classic instrument versus new handheld robotic device for laparoscopy. Surg Innov 2016; 23: 52-61

[19] Aggarwal R, Grantcharov T, Moorthy K et al. Toward feasible, valid, and reliable video-based assessments of technical surgical skills in the operating room. Ann Surg 2008; 247: 372-379

[20] Hasson HM, Jason $\mathrm{H}$. Information retention and skill acquisition after CME meetings. Laparosc Today 2007; 6: 4-6; 2012; 26: 2961-2968

[21] Kunert W, Storz P, Kirschniak A. For 3D laparoscopy: a step towards advanced surgical navigation: how to get maximum benefit from 3D vision. Surg Endosc 2013; 27: 696-699

[22] Alaraimi B, El Bakbak W, Sarker S et al. A randomized prospective study comparing acquisition of laparoscopic skills in three-dimensional (3D) vs. two-dimensional (2D) laparoscopy. World J Surg 2014; 38: 27462752

[23] Wilhelm D, Reiser S, Kohn $\mathrm{N}$ et al. Comparative evaluation of HD 2D/3D laparoscopic monitors and benchmarking to a theoretically ideal 3D pseudodisplay: even well-experienced laparoscopists perform better with 3D. Surg Endosc 2014; 28: 2387-2397

[24] Cicione A, Autorino R, Breda A et al. Three-dimensional vs. standard laparoscopy: comperative assessment using a validated programm for laparoscopic urologic skills. Urology 2013; 82: 1444-1450

[25] Kneist W, Huber T, Paschold M et al. 3D virtual reality laparoscopic simulation in surgical education - results of a pilot study. Zentralbl Chir 2016; 141: 297-301

[26] LaGrange CA, Clark C], Gerber EW et al. Evaluation of three-dimensional vision laparoscopic modalities: robotics versus three-dimensional vision laparoscopy versus standard laparoscopy. J Endourol 2008; 22: 511-516

[27] Sun CC, Chiu AW, Chen KK et al. Assessment of a three-dimensional operating system with skill tests in a pelvic trainer. Urol Int 2000; 64: 154158

[28] Mueller M, Camartin C, Dreher E et al. Three-dimensional laparoscopy. Gadget or progress? A randomized trial on the efficacy of three-dimensional laparoscopy. Surg Endosc 1999; 13: 469-472

[29] Smith R, Schwab K, Day A et al. Effect of passive polarizing three-dimensional displays on surgical performance for experienced laparoscopic surgeons. Br J Surg 2014; 101: 1453-1459

[30] Tanagho YS, Andriole GL, Paradis AG et al. 2D versus 3D visualization: impact on laparoscopic proficiency using the fundamentals of laparoscopic surgery skill set. J Laparoendosc Adv Surg Tech A 2012; 22: 865870

[31] Honeck P, Wendt-Nordahl G, Rassweiler J et al. Three-dimensional laparoscopic imaging improves surgical performance on standardized exvivo laparoscopic tasks. J Endourol 2012; 26: 1085-1088
[32] Silvestri M, Simi M, Cavallotti C et al. Autostereoscopic three-dimensional viewer evaluation through comparison with conventional interfaces in laparoscopic surgery. Surg Innov 2011; 18: 223-230

[33] Feng C, Rozenblit JW, Hamilton AJ. A computerized assessment to compare the impact of standard, stereoscopic, and high-definition laparoscopic monitor displays on surgical technique. Surg Endosc 2010; 24: 2743-2748

[34] Supe AN, Kulkarni GV, Supe PA. Ergonomics in laparoscopic surgery. J Minim Access Surg 2010; 6: 31-36

[35] Shore EM, Lefebvre GG, Husslein $\mathrm{H}$ et al. Designing a standardized laparoscopy curriculum for gynecology residents: a Delphi approach. J Grad Med Educ 2015; 7: 197-202

[36] van Bergen P, Kunert W, Bessell J et al. Comparative study of two-dimensional and three-dimensional vision systems for minimally invasive surgery. Surg Endosc 1998; 12: 948-954

[37] Sahu D, Mathew MJ, Reddy PK. 3D laparoscopy - help or hype; initial experience of a tertiary health centre. J Clin Diagn Res 2014; 8: NC01NCO3

[38] Falk V, Mintz D, Grünenfelder J et al. Influence of three-dimensional vision on surgical telemanipulator performance. Surg Endosc 2001; 15: $1282-1288$

[39] Kihara K, Fujii Y, Masuda $\mathrm{H}$ et al. New three-dimensional head-mounted display system, TMDU-S-3D system, for minimally invasive surgery application: procedures for gasless single-port radical nephrectomy. Int J Urol 2012; 19: 886-889

[40] Zdichavsky M, Schmidt A, Luithle T et al. Three-dimensional laparoscopy and thoracoscopy in children and adults: a prospective clinical trial. Minim Invasive Ther Allied Technol 2015; 24: 154-160

[41] Way LW, Stewart L, Gantert W et al. Causes and prevention of laparoscopic bile duct injuries: analysis of 252 cases from a human factors and cognitive psychology perspective. Ann Surg 2003; 237: 460-469

[42] Chan AC, Chung SC, Yim AP et al. Comparison of two-dimensional vs. three-dimensional camera systems in laparoscopy surgery. Surg Endosc 1997; 11: 438-440

[43] Taffinder N, Smith SG, Huber J et al. The effect of a second-generation $3 \mathrm{D}$ endoscope on the laparoscopic precision of novices and experienced surgeons. Surg Endosc 1999; 13: 1087-1092

[44] Hanna GB, Shimi SM, Cuschieri A. Randomised study of influence of twodimensional versus three-dimensional imaging on performance of laparoscopic cholecystectomy. Lancet 1998; 351: 248-251

[45] Votanopoulos K, Brunicardi F, Thornby J. Impact of three dimensional vision in laparoscopic training. World J Surg 2008; 32: 110-118

[46] Tevaearai HT, Mueller XM, Segesser LK. 3-D vision improves performance in a pelvic trainer. Endoscopy 2000; 32: 464-468

[47] Lusch A, Bucur PL, Menhadji AD et al. Evaluation of the impact of threedimensional vision on laparoscopic performance. J Endourol 2014; 28 : 261-266 